\title{
Use of Ultrasonic Baths for Analytical Applications: A New Approach for Optimisation Conditions
}

\author{
Clésia C. Nascentes ${ }^{a}$, Mauro Korn ${ }^{b}$, Clarivaldo S. Sousa ${ }^{c}$ and Marco A. Z. Arruda ${ }^{a^{*}}$ \\ anstituto de Química, Universidade Estadual de Campinas, CP6154, 13083-970, Campinas - SP, Brazil. \\ ${ }^{\mathrm{b}}$ Departamento de Ciências Exatas e da Terra, Universidade do Estado da Bahia, Salvador - BA, Brazil. \\ ${ }^{\mathrm{c}}$ Instituto de Química, Universidade Federal da Bahia, Salvador - BA, Brazil
}

\begin{abstract}
Com o emprego de um método simples e rápido, são propostas algumas condições de otimização para a obtenção de máxima intensidade de cavitação em banhos de ultra-som. Os parâmetros estudados foram: volume de água dentro do banho, temperatura, concentração de detergente, posição vertical e horizontal dos tubos no banho, número de tubos dentro do banho, tempo de sonicação e substituição da água do banho. Os resultados obtidos para os banhos de ultra-som estudados (Neytech e Cole-Parmer) permitiram estabelecer as seguintes condições para máxima intensidade de cavitação: $1 \mathrm{~L}$ de água à temperatura ambiente; $0,2 \%$ (v/v) de detergente; posição central e ao fundo do banho. Somente 1 tubo deve ser usado por vez dentro do banho durante a aplicação do ultra-som. A intensidade de cavitação foi linear com o tempo de sonicação até 10 minutos e a substituição de água durante a sonicação melhorou a reprodutibilidade. Esse sistema de troca contínua de água permite a sonicação de até 6 amostras consecutivamente sem mudanças no volume total de água.
\end{abstract}

Optimisation conditions for obtaining maximum cavitation intensity in ultrasonic baths are proposed using a simple and fast method. Parameters such as water volume, temperature, detergent concentration, horizontal and vertical positions, number of tubes in the bath, sonication time and bath water substitution were studied. The results obtained for both baths studied (Neytech and Cole-Parmer) lead to the following conditions for maximum cavitation intensity: $1 \mathrm{~L}$ of water at room temperature, $0.2 \%(\mathrm{v} / \mathrm{v})$ of detergent, central position on the bottom of the tank. Only one tube at a time should be used inside the bath during the ultrasound application. The cavitation intensity was linear with the sonication time up to 10 minutes and the water substitution during the sonication improved reproducibility. This system using continuous water change makes possible the sonication of 6 consecutive samples, without changes in the water volume.

Keywords: ultrasonic bath, analytical application, cavitation, iodine, hydrogen peroxide

\section{Introduction}

Ultrasound energy has been found to be an efficient way to improve the performance of several different applications of analytical chemistry, such as extractions of inorganic and organic compounds ${ }^{1,2}$, slurry dispersion ${ }^{3}$, homogenisation ${ }^{4}$, and other applications ${ }^{5-8}$.

The sonochemical reaction is considered to originate from acoustic cavitation. This process can be characterised by the formation, growth and implosive collapse of gas vacuoles in a solution. The cavity growth depends on the intensity of sound ${ }^{9}$. The collapse may proceed as an adiabatic compression and generate high temperature and pressure $^{10}$, while the implosion of cavities establishes an unusual environment for chemical reactions ${ }^{9,11}$. The high

*e-mail: zezzi@iqm.unicamp.br temperatures and pressures generated lead to formation of free radicals and other compounds; the sonication of pure water leads to the thermal dissociation of water vapour into $\mathrm{H}$ atoms and $\mathrm{OH}$ radicals, and the recombination of the latter tends to form hydrogen peroxide ${ }^{9,11,12}$. In addition, when for example, an aqueous solution of potassium iodide is sonicated, iodine radicals are liberated ${ }^{4}$.

The principal instruments used in sonochemistry are ultrasonic baths and ultrasonic probes ${ }^{13}$. Ultrasound generators transform electrical energy into ultrasonic energy, which is a mechanical energy. The efficiency of the energy transformation depends not only on the equipment itself, but also on the ultrasound application conditions ${ }^{14}$. The effect of high-intensity ultrasound depends on many variables. Among the most important variables are the reaction medium characteristics (viscosity, surface tension, vapour pressure, nature and concentration of the dissolved 
gas, presence of solid particles, etc) treatment parameters (pressure and temperature), ultrasound generator performance (frequency, power input), size and geometry of the treatment vessel ${ }^{15}$.

The energy of ultrasound is not uniformly available from the ultrasonic bath. Only a small fraction of the total liquid volume in the immediate vicinity of the ultrasound source experiments the effects of cavitation. The intensity of ultrasound is continuously attenuated by the molecules present in the liquid due to various cohesive forces acting on the liquid $^{16}$. The ultrasonic intensity profile in the baths depends entirely on the design and location of the transducers. For commercially available ultrasonic baths a variety of transducers with different configurations are used ${ }^{17}$.

The results of a sonochemical reaction largely depend on the placement of the reaction vessel in the bath. In order to study the effect of ultrasound on a reaction, a reproducible exposition to ultrasound waves is necessary. For this purpose it becomes essential to identify the optimum sonication conditions individually for each ultrasonic bath ${ }^{13}$.

A great variety of techniques for the measurement of ultrasonic or cavitation intensity has been listed in the literature $^{18}$, such as chemical reactions ${ }^{19}$, elastic sphere radiometry ${ }^{20}$, aluminium foil erosion ${ }^{21}$, calorimetric and optical methods ${ }^{16,19,22}$, thermoprobes ${ }^{21}$ and others ${ }^{18,23}$.

In view to know the better conditions for maximum cavitation and its spatial distribution in ultrasonic baths in order to maximise the ultrasound effects for analytical applications, the aim of this work was proposed a simple spectrophotometric methodology to measure cavitation intensity in different conditions, using two chemical reactions: formation of $\mathrm{I}_{2}$ (from $\mathrm{KI}$ solution) and $\mathrm{H}_{2} \mathrm{O}_{2}$ (from water).

\section{Experimental}

\section{Instruments and apparatus}

Two ultrasonic baths, a Neytech model 28H (USA) and a Cole-Parmer model R8860 were used at a frequency of $47 \pm 3 \mathrm{kHz}$. In order to monitor the reactions used to follow the sonochemical process an spectrophotometer (model 432 - Femto, São Paulo, Brazil) set at $352 \mathrm{~nm}$ or $426 \mathrm{~nm}$ for $\mathrm{I}_{2}$ or $\mathrm{H}_{2} \mathrm{O}_{2}$ colour formation, respectively, was used. Hydrogen peroxide determination was also carried out using a monosegmented system described elsewhere 24 .

\section{Standards and reagents}

All solutions were prepared with analytical reagentgrade chemicals (Merck, Darmstadt, Germany). Deionised water was used throughout. To prepare the calibration curve for hydrogen peroxide monitoring, a concentrated $\mathrm{H}_{2} \mathrm{O}_{2}$ $(30 \% \mathrm{v} / \mathrm{v})$ was used to prepare the working solutions $(500$ $-2000 \mu \mathrm{g} \mathrm{L}^{-1}$ ) daily by serial dilutions with water. Also, 1 mol L ${ }^{-1} \mathrm{NaOH}, 5 \times 10^{-4} \mathrm{~mol} \mathrm{~L}^{-1}$ Tiron and $10 \mu \mathrm{g} \mathrm{L}^{-1} \mathrm{Co}$ [from $\mathrm{Co}\left(\mathrm{NO}_{3}\right)_{2} \cdot 6 \mathrm{H}_{2} \mathrm{O}$ ] were prepared and used for the monosegmented system.

KI (0.29 mol L-1) was prepared each two days by dissolving the respective mass with water and a $3.67 \times 10^{-3}$ mol L-1 $\left(\mathrm{NH}_{4}\right)_{6} \mathrm{Mo}_{7} \mathrm{O}_{24}$ was prepared from a stock solution by serial dilutions with water. These solutions were prepared for monitoring the sonochemical process.

\section{Procedure}

In order to investigate the ultrasound pattern distribution inside the baths, first the positions of the tubes in two different baths (Neytech and Cole-Parmer) was fixed by using a piece of polyethylene foam where up to 9 tubes were supported (see Figure 1). In this way, different parameters were studied by using an unvariate method, such as water volume in the baths ( 1 to $2 \mathrm{~L}$ and 0.4 to $1.3 \mathrm{~L}$ for Neytech and Cole-Parmer baths, respectively), water temperature $\left(26\right.$ to $\left.36^{\circ} \mathrm{C}\right)$, detergent concentration in water $(0$ to $0.4 \% \mathrm{v} / \mathrm{v})$, tube height from the bottom of tank ( 0 to $2 \mathrm{~cm}$ ), number of tubes in the bath (1 to 9), position of the tube(s), sonication time (1 to 10 min) and bath water substitution.

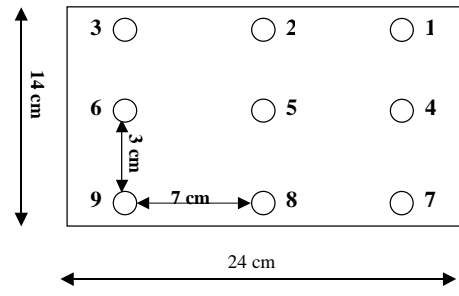

(a)

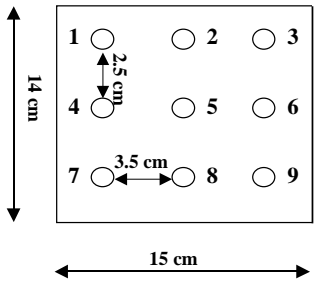

(b)
Figure 1. Tube positions inside the ultrasonic bath for ultrasound distribution studies for (a) Neytech bath and (b) Cole-Parmer bath. $1-9$ correspond to different positions of the tubes.

All parameters were evaluated by variation of the yellow colour, followed spectrophotometricaly at $352 \mathrm{~nm}$ from $\mathrm{I}_{2}$ reaction formation ${ }^{4}$ by sonication of a solution of $5 \mathrm{~mL} \mathrm{KI}$ and $0.1 \mathrm{~mL}$ ammonium molybdate for 5 minutes. Each condition applied produced different $\mathrm{I}_{2}$ concentrations. For confirmation, some tests were also used to determine the $\mathrm{H}_{2} \mathrm{O}_{2} 25$ formed from water sonication.

\section{Results and Discussion}

\section{Reactions used}

The $\mathrm{I}_{2}$ formation can occur by two forms 4,26 : 
by forming radical like $\mathrm{I}^{\bullet}$ (reactions 1 and 2 ) and by redox reaction between $\mathrm{I}^{-}$and $\mathrm{H}_{2} \mathrm{O}_{2}$ (reactions 3, 4 and 5).

$$
\begin{aligned}
& \mathrm{KI} \rightarrow \mathrm{K}^{\bullet}+\mathrm{I}^{\bullet} \\
& \mathrm{I}^{\bullet}+\mathrm{I}^{\bullet} \rightarrow \mathrm{I}_{2} \\
& \mathrm{H}_{2} \mathrm{O} \rightarrow \mathrm{H}^{\bullet}+{ }^{\bullet} \mathrm{OH} \\
& \mathrm{HO}^{\bullet}+{ }^{\bullet} \mathrm{OH} \rightarrow \mathrm{H}_{2} \mathrm{O}_{2} \\
& \mathrm{H}_{2} \mathrm{O}_{2}+2 \mathrm{I}^{-}+2 \mathrm{H}^{+} \rightarrow \mathrm{I}_{2}+2 \mathrm{H}_{2} \mathrm{O}
\end{aligned}
$$

In the determination of the $\mathrm{H}_{2} \mathrm{O}_{2}$ formed (reactions 3 and 4), an indirect method was used ${ }^{25}$. This reaction is based on catalytic effect of cobalt in the oxidation of Tiron by hydrogen peroxide. Reaction 6 is shown below:

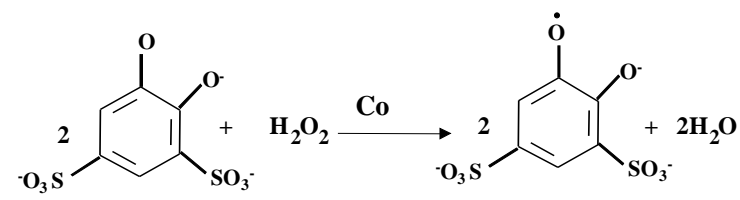

\section{Effects of the water volume in the baths}

Cavitation intensity in organic liquids is lower than water and this intensity change between different solvents used. Liquids of cyclic structure (such as styrene, toluene, and xylene) tend to cavitate most intensity. On the other hand, liquids presenting carboxylic acids and aliphatic amines tend to cavitate weakly ${ }^{27}$. Although the $\mathrm{I}_{2}$ method never was used to this purposed, seems to be that it can be used to measure cavitation intensity in some organic solvents or mixing these solvents with water. However, cavitation intensity may be lower when compared when only water is used ${ }^{27}$, as well as longer times of sonication can be required.

Because this work was proposed for analytical applications and most of these applications were made in aqueous solution, only water was investigated. In this way, different levels of water were used due to the different capacities related to each bath. However, the best results were obtained with $1 \mathrm{~L}$ of water for both baths. The results are presented in Table 1 and the measurements were obtained by applying the iodine method. In this sense, higher absorbances mean a more intense cavitation process. In addition, with $1 \mathrm{~L}$ of water low Relative Standard Deviation - RSD ( ca. 5 and $12 \%$ for the Neytech and ColeParmer baths, respectively) for the measurements were obtained with the spectrophotometric method.

It is interesting to note that since the Neytech bath has two ceramics (piezo electrics) and Cole-Parmer bath has
Table 1. Effects of the water volume inside the ultrasonic baths on the absorbances for the $\mathrm{I}_{2}$ method.

\begin{tabular}{cccccc}
\hline \multicolumn{3}{c}{ Cole-Parmer bath } & \multicolumn{3}{c}{ Neytech bath } \\
\hline Vol. (L) & $\mathrm{A}^{\mathrm{a}}$ & \%RSD & Vol. (L) & $\mathrm{A}^{\mathrm{a}}$ & \%RSD \\
0.4 & 0.064 & 17.43 & 1.00 & 1.162 & 4.96 \\
0.6 & 0.031 & 22.89 & 1.25 & 0.005 & 16.09 \\
0.8 & 0.173 & 11.61 & 1.50 & 0.038 & 23.91 \\
1.0 & 0.507 & 11.99 & 1.75 & 0.085 & 14.76 \\
1.2 & 0.386 & 10.53 & 2.00 & 0.299 & 14.29 \\
1.3 & 0.228 & 10.12 & & & \\
aMean absorbance obtained with $\mathrm{n}=5$. &
\end{tabular}

only one for producing the ultrasound, the maximum $\mathrm{I}_{2}$ quantities formed for the Neytech bath are nearly the double those obtained for Cole-Parmer bath. Ultrasonic baths are usually designed to produce a standing-wave pattern within the cleaning liquid, with maximum ultrasound intensity generated at the antinodes in the pattern ${ }^{28}$. This pattern can be seen by visual inspection of the cleaning liquid surface; such inspection also reveals that the pattern shifts across the surface with time and therefore is not a true standing-wave pattern ${ }^{28}$. According some authors ${ }^{18,20,4}$, if the water level is significantly lower than half of the ultrasound wavelength $(\lambda)$ in water, the ultrasound intensity diminishes with an increase in the distance from the source. When the water level was $\geq \lambda / 2$, intensity profiles of standing-waves were observed. At a water level of $c a . \mathrm{n} \mathrm{x}$ $\lambda / 2$ resonating standing-waves are achieved. The $\lambda$ could be calculated with the frequency of the bath and the sound velocity in the media. However, the velocity of an ultrasonic wave in liquids is dependent on the temperature and densities $^{29}$. In this case, it is difficult to calculate $\lambda$ exactly because the room temperature of water varied during the day and the frequency supplied by manufacturer has a variation of $\pm 6 \%$. In this sense, the better way to obtain the maximum cavitation conditions for analytical applications is experimental.

\section{Effects of the water temperature}

Since a temperature control does not exist in the ColeParmer R8860 ultrasonic bath model, this test was only performed with the Neytech bath. The temperature range $\left(26-36^{\circ} \mathrm{C}\right)$ was chosen because in different ultrasound applications an environmental temperature $\left(26^{\circ} \mathrm{C}\right)$ is used while some authors suggest that the effect of high temperatures (above $40{ }^{\circ} \mathrm{C}$ ) decreases the ultrasound intensity ${ }^{14,19,30}$. According to Table 2, although a higher RSD was obtained with environmental temperature $\left(26^{\circ} \mathrm{C}\right)$, the absorbances achieved for the temperatures studied were not different at the $95 \%$ confidence interval. In this way, for simplicity, the temperature of $26^{\circ} \mathrm{C}$ was chosen for other experiments. 
Table 2. Effects of the water temperature on the absorbances for the $\mathrm{I}_{2}$ method for Neytech bath.

\begin{tabular}{ccc}
\hline Temperature $\left({ }^{\circ} \mathrm{C}\right)$ & $\mathrm{A}^{\mathrm{a}}$ & \%RSD \\
\hline 26 & 1.144 & 5.33 \\
31 & 1.255 & 1.84 \\
36 & 1.202 & 1.37 \\
\hline
\end{tabular}

a Mean absorbance obtained with $\mathrm{n}=5$.

\section{Effects of the detergent concentration in water}

At higher viscosities the cavitation process is more difficult to be induced (greater power input is required) and the number of cavitating bubbles per unit volume is reduced ${ }^{15,17}$. With the use of a detergent, the surface tension is decreased, facilitating ultrasound propagation ${ }^{31}$ and producing better cavitation. Since it is necessary for the rarefaction pressure to overcome the cohesive forces in the liquid in order to be able to generate a bubble any increase in viscosity or surface tension will naturally lead to an increase in the amount of energy needed to separate the liquid $^{17}$. This is confirmed according Table 3 where, with the use of a detergent at 0.2 or $0.4 \% \mathrm{v} / \mathrm{v}$, an increase of $c a$. 33 and $26 \%$, respectively in the absorbances were obtained, related to those obtained without detergent. In this way, the detergent concentration was fixed in $0.2 \% \mathrm{v} / \mathrm{v}$.

Table 3. Effects of the detergent concentration on the absorbances for the $\mathrm{I}_{2}$ method for Neytech bath.

\begin{tabular}{ccc}
\hline Detergent $(\% \mathrm{v} / \mathrm{v})$ & $\mathrm{A}^{\mathrm{a}}$ & \%RSD \\
\hline 0 & 1.007 & 5.64 \\
0.2 & 1.336 & 1.91 \\
0.4 & 1.265 & 1.34
\end{tabular}

${ }^{\mathrm{a}}$ Mean absorbance obtained with $\mathrm{n}=5$.

\section{Effects of tube height}

In order to verify the vertical distribution of the ultrasound, a study was performed using the Neytech bath. In this study the tube height was varied from 0,1 or $2 \mathrm{~cm}$ from the bottom of the tank. Pugin has shown that the ultrasonic intensity within a bath varies with distance from the transducers ${ }^{21}$. As can be seen in the Table 4, when the tubes were positioned at 1 or $2 \mathrm{~cm}$ from the bottom of the tank, lower results were obtained, related to the bottom position. This can be explained due to the distance of these tubes from the ultrasound source. On the other hand, when the tube was positioned in the bottom position, an increase in the absorbance up to 10 times was achieved. In this way, the tubes were always located in this position.

\section{Effects of the number of tubes in the bath}

A great amount of tubes inside the bath provokes ultrasound wave reflections, reducing the efficiency of the
Table 4. Effects of tubes height on the absorbances for the $I_{2}$ method by using the Neytech bath.

\begin{tabular}{ccc}
\hline Height $(\mathrm{cm})$ & $\mathrm{A}^{\mathrm{a}}$ & \%RSD \\
\hline 0 & 1.267 & 4.55 \\
1 & 1.071 & 5.50 \\
2 & 0.119 & 15.57 \\
\hline
\end{tabular}

aMean absorbance obtained with $\mathrm{n}=5$.

sonication process. For this study, up to 9 tubes were placed in the positions specified in Figure 1. According to Tables 5 and 6, a decrease in the absorbance was obtained ( $c a .5$ and 12 times in the absorbance for Cole-Parmer and Neytech baths, respectively) with an increase in the number of the tubes inside the bath. Also, it is interesting to note that, for the Cole-Parmer bath, depending on the tube distribution, the optimum position for cavitation is modified (see Table 5 , rows 4 and 6). These results also show that, for analytical applications, only one tube and the same position should be used in order to obtain precise results.

\section{Horizontal distribution of the ultrasound}

The study was realised in two water volumes: $1 \mathrm{~L}$ (maximum cavitation intensity in the central point) and maximum capacity of the bath $(2$ and $1.3 \mathrm{~L}$ for Neytech and Cole-Parmer baths, respectively). The ultrasound distribution in the baths can be seen in Figure 2 and 3 for Neytech and Cole-Parmer baths, respectively. Although these two baths present the same best cavitation position (point 5, Figure 1a and $1 \mathrm{~b}$ ) when used with $1 \mathrm{~L}$ of water, the shape of the ultrasound distribution in the Cole-Parmer bath seems to be more uniform, related to the Neytech bath. For baths fitted with a single transducer (Cole-Parmer bath), the maximum ultrasonic intensity is found above the transducer; for baths equipped with two transducers (Neytech bath) the maximum intensity is found midway between the two acoustic wave generators ${ }^{21}$. Position 5 is located above the transducer in the Cole-Parmer bath and between the two transducers in the Neytech bath. The spatial distribution of the ultrasonic intensity is significantly affected by a variety of factors, including water volume in the bath, operating voltage of the transducer(s), and shape and position of the flask in the bath ${ }^{28}$, as can be observed by comparing the Figure 2(a) and 2(b) or 3(a) and 3(b). The change in the water volume in the bath completely modifies the horizontal distribution of the cavitation. When the total volume was used, the Cole-Parmer bath presented two points of maximum cavitation intensity (positions 5 and 6, Figure 1b) and the Neytech bath presented maximum cavitation at a different position (8, Figure 1a). The susceptibility of the ultrasonic field within the bath to these various external factors leads to considerable difficulties 
Table 5. Effects of the number of tubes in the Cole-Parmer bath.

\begin{tabular}{|c|c|c|c|c|c|c|c|c|c|}
\hline Position & $9^{\mathrm{a}}$ & 7 & $5^{b}$ & $5^{b}$ & 4 & $3^{\mathrm{b}}$ & $3^{\mathrm{b}}$ & 2 & $1^{\mathrm{c}}$ \\
\hline 1 & $0.031^{\mathrm{d}}$ & & & 0.067 & & & & & 0.154 \\
\hline 2 & 0.052 & & 0.037 & & & & 0.025 & & 0.025 \\
\hline 3 & 0.029 & 0.022 & & 0.060 & & & & & 0.022 \\
\hline 4 & 0.064 & 0.016 & 0.018 & & 0.034 & 0.036 & & & 0.325 \\
\hline 5 & 0.186 & 0.185 & 0.084 & 0.264 & 0.032 & 0.661 & 0.632 & 0.730 & 0.869 \\
\hline 6 & 0.165 & 0.130 & 0.228 & & 0.023 & 0.135 & & 0.022 & 0.035 \\
\hline 7 & 0.028 & 0.022 & & 0.040 & & & & & 0.040 \\
\hline 8 & 0.050 & 0.102 & 0.271 & & 0.151 & & 0.271 & & 0.270 \\
\hline 9 & 0.030 & 0.138 & & 0.095 & & & & & 0.024 \\
\hline
\end{tabular}

$\overline{{ }^{a}}$ Number of tubes inside the bath simultaneously; ${ }^{b}$ Three or five tubes in different positions; ${ }^{\mathrm{c}}$ One tube sonicated each time; ${ }^{\mathrm{d}}$ Mean absorbance obtained with $\mathrm{n}=3$.

Table 6. Effects of the number of tubes in the Neytech bath.

\begin{tabular}{|c|c|c|c|c|c|c|c|c|c|}
\hline Position & $9^{a}$ & 7 & $5^{b}$ & $5^{b}$ & 4 & $3^{b}$ & $3^{b}$ & 2 & $1^{\mathrm{c}}$ \\
\hline 1 & $0.058^{\mathrm{d}}$ & & & 0.040 & & & & & 0.063 \\
\hline 2 & 0.024 & & 0.023 & & & 0.007 & & & 0.033 \\
\hline 3 & 0.018 & 0.032 & & 0.024 & & & & & 0.020 \\
\hline 4 & 0.041 & 0.026 & 0.037 & & 0.039 & & 0.080 & & 0.018 \\
\hline 5 & 0.020 & 0.189 & 0.670 & 0.448 & 0.792 & 0.958 & 1.030 & 1.171 & 1.280 \\
\hline 6 & 0.033 & 0.021 & 0.023 & & 0.045 & & 0.013 & 0.015 & 0.034 \\
\hline 7 & 0.050 & 0.035 & & 0.040 & & & & & 0.024 \\
\hline 8 & 0.030 & 0.019 & 0.048 & & 0.027 & 0.007 & & & 0.039 \\
\hline 9 & 0.015 & 0.027 & & 0.020 & & & & & 0.032 \\
\hline
\end{tabular}

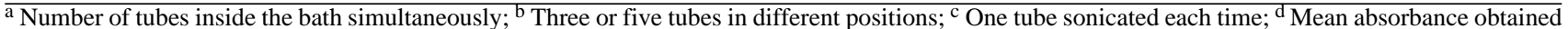
with $\mathrm{n}=3$.

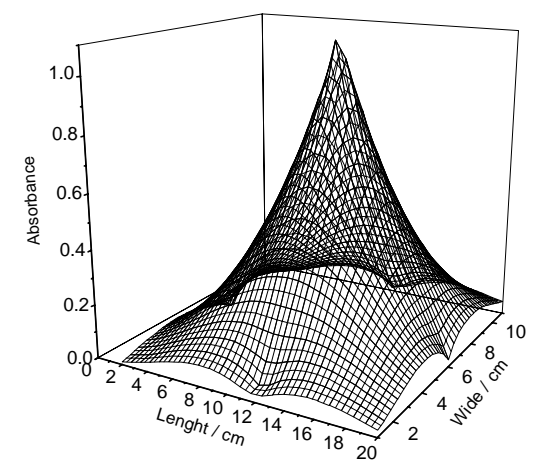

(a)

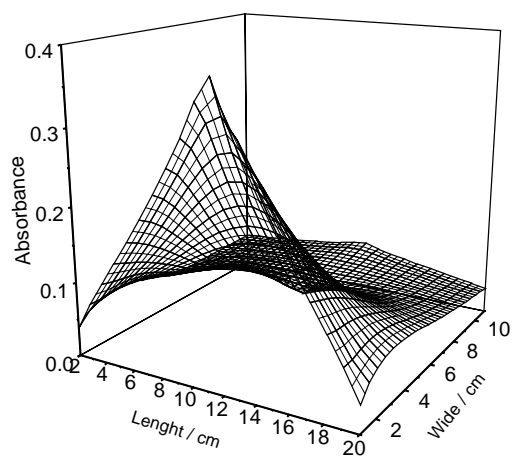

(b)

Figure 2. Spatial distribution of the ultrasonic field in the Neytech bath: (a) using $1 \mathrm{~L}$ of water in the bath and (b) using the total volume $(2 \mathrm{~L})$ of water in the bath.

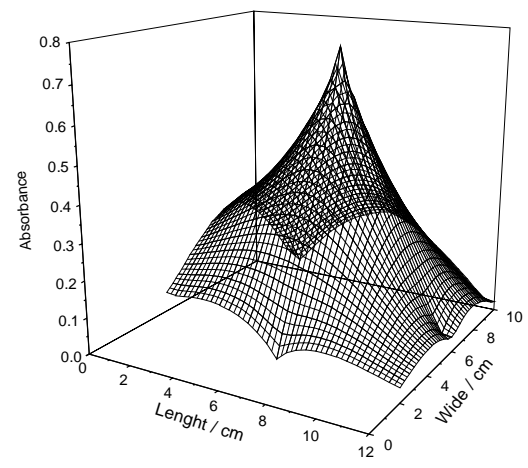

(a)

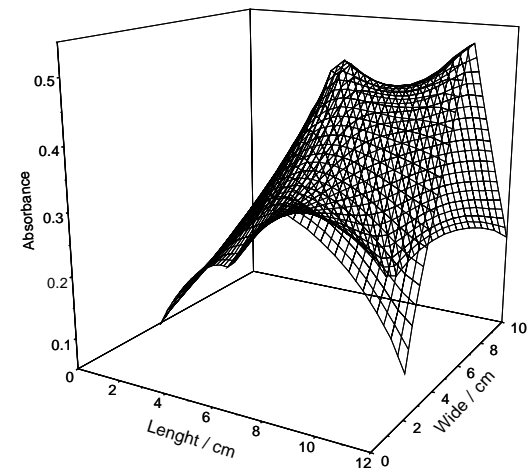

(b)

Figure 3. Spatial distribution of the ultrasonic field in the Cole-Parmer bath: (a) using $1 \mathrm{~L}$ of water in the bath and (b) using the total volume (1.3 $\mathrm{L}$ ) of water in the bath. 
in quantifying the amount of power dissipated, and the cavitation generated, within a reaction vessel placed in the bath. This also leads to problems with reproducibility; reaction vessels of similar shape need to be placed in the same position in the bath for each experiment if reproducible and consistent results are required ${ }^{28}$.

For the Neytech bath with $1 \mathrm{~L}$ water, the ultrasound distribution was obtained by the $\mathrm{I}_{2}$ method and confirmed by the amount of $\mathrm{H}_{2} \mathrm{O}_{2}$ formed $\left(950 \mu \mathrm{g} \mathrm{L}^{-1}\right.$ at the point 5) during the cavitation process.

\section{Sonication time vs. cavitation intensity}

In order to verify the efficiency of the sonication time, different sonication times were applied (1-10 $\mathrm{min}$ ) at the tube positioned at point 5 (see Figure 1). Longer times were not tested since higher absorbances $\left(>1.8 \mathrm{~A}\right.$ ) for the $\mathrm{I}_{2}$ method were produced, compromising the measurements and giving higher RSD (more than 50\%). Comparing both baths, slight differences were observed, presenting a linear correlation coefficient for $\mathrm{I}_{2}$ results of 0.990 and 0.998 for Neytech and Cole-Parmer baths, respectively.

\section{Effects of substitution of water in the baths}

Ultrasonic baths are warmed up during use, particularly over an extended period of time. This leads to inconsistent results when working at room temperature or below ${ }^{28}$. This can be resolved by using a thermostated bath or by substitution of the bath water.

As can be seen in Table 7, a great difference exists in the results when water was continuously changed during the sonication process. The water was pumped at $18.2 \mathrm{~mL} \mathrm{~min}^{-1}$, being inserted at position 9 and discarded at position 1 (see Figure 1a). With this simple system, up to 6 samples were sonicated consecutively with a RSD of only $5.3 \%$. Instead, when the water was not changed a RSD of $45 \%$ was obtained with a gradual decrease in the absorbances (from 1.156 to $0.277 \mathrm{~A}$ for 5 consecutive sonications).

Table 7. Effects of water substitution on the absorbance for the $I_{2}$ method by using the Neytech bath.

\begin{tabular}{ccccc}
\hline Samples & \multicolumn{2}{c}{ without water substitution } & \multicolumn{2}{c}{ with water substitution } \\
\hline & $\mathrm{A}^{\mathrm{a}}$ & \%RSD & $\mathrm{A}^{\mathrm{a}}$ & \%RSD \\
\hline 1 & 1.156 & 10.45 & 1.057 & 8.42 \\
2 & 0.932 & 21.43 & 1.131 & 5.08 \\
3 & 0.879 & 30.83 & 1.149 & 4.21 \\
4 & 0.568 & 42.38 & 1.097 & 3.11 \\
5 & 0.277 & 13.16 & 1.054 & 4.07 \\
6 & & & 0.993 & 4.20 \\
Mean & 0.762 & & 1.080 & \\
\%RSD & 44.99 & & 5.31 & \\
\hline
\end{tabular}

\section{Conclusions}

The proposed method offers advantages to other methods presented in the literature which use thermoprobes, aluminium foil erosion, calorimetric or optical probes. In the present method, the system purposed can simulate the real conditions for analytical application. It optimisation was carried out with the same flask which for example, it can be also used for extraction procedures. In addition, this method requires only a spectrophotometer, make possible it uses in any laboratory in an easy way.

Characterisation of the ultrasonic bath is very important for sonochemical reactions. The conditions of maximum cavitation intensity can be different for each ultrasonic bath and, due to this behaviour, it is very difficult to compare the results obtained with different ultrasonic baths even using the same conditions. In analytical chemistry, when reproducible and accurate results are required, the experimental conditions (such as water volume, temperature, detergent concentration, vertical and horizontal positions, number of tubes, sonication time) must be studied, established and rigorously reproduced for each experiment. An innovative way to study these conditions was employed in the present work by spectrophotometricaly following the $\mathrm{I}_{2}$ formation from free radical of iodine $\left(\mathrm{I}^{\bullet}\right)$ obtained after sonication of a KI solution.

In this way, the use of ultrasonic energy in analytical chemistry can be an alternative related to other energy forms, since some applications (such as extractions, homogenisation, lixiviation and others) can be easily performed, with simplicity and low cost.

\section{Acknowledgements}

The authors are grateful to the Conselho Nacional de Desenvolvimento Científico e Tecnológico (CNPq, Brasília, Brazil) for fellowships to C.C.N., M. K. and M.A.Z.A., and to the Fundação de Amparo à Pesquisa do Estado de São Paulo (FAPESP, São Paulo, Brazil) and PADCTIII (CNPq, Brasília, Brazil) for financial support. We also thank Prof. C. H. Collins for language assistance.

\section{References}

1. Kunina, D. M.; Karyakin, A. V.; Gribovskaya, I. F. Zhur. Anal. Khim. 1985, 40, 1184.

2. Gomez-Ariza, J. L.; Morales, E.; Beltran, R.; Giraldez, I.; Ruiz-Benitez, M. Analyst 1995, 120, 1171.

3. Mierzwa, J.; Sun, Y. C.; Yang, M. H. Anal. Chim. Acta 1997, 355, 277.

4. Henglein, A. Ultrasonics, 1987, 25, 6. 
5. Vinodgopal, K.; Peller, J.; Makogon, O.; Kamat, P. V. Water Res. 1998, 32, 3646.

6. Pack, B. W.; Ray, S. J.; Potyrailo, R. A.; Hieftje, G. M. Appl. Spectrosc. 1998, 52, 1515.

7. Buldini, P. L.; Mevoli, A.; Sharma, J. L. Talanta 1998, 47, 203.

8. Fransson B.; Ragnarsson, U. J. Chromatogr. 1998, $827,31$.

9. Suslick, K. S. Scient. Amer. 1989, Feb, 80.

10. Mizukoshi, Y.; Nakamura, H.; Bandow, H.; Maeda, Y.; Nagata, Y. Ultrason. Sonochem. 1999, 6, 203.

11. Carvalho, L. R. F.; Souza, S. R.; Martinis, B. S.; Korn, M. Anal. Chim. Acta 1995, 317, 171.

12. Wakeford, C. A.; Blackburn, R.; Lickiss, P. D. Ultrason. Sonochem. 1999, 6, 141.

13. Soudagar, S. R.; Samant, S. D. Ultrason. Sonochem. 1995, 2, S49.

14. Raso, J.; Mañas, P.; Pagán, R.; Sala, F. J. Ultrason. Sonochem. 1999, 5, 157.

15. Berlan, J.; Mason, T. J. Ultrasonics 1992, 30, 203.

16. Majumdar, S.; Kumar, P. S.; Pandit, A. B. Ultrason. Sonochem. 1998, 5, 113.

17. Mason, T. J. Sonochemistry: The uses of ultrasound in chemistry; Royal Society of Chemistry; Cambridge, 1990.
18. Faid, F.; Contamine, F.; Wilhelm, A. M.; Delmas, H. Ultrason. Sonochem. 1998, 5, 119.

19. Kimura, T.; Sakamoto, T.; Leveque, J. M.; Sohmiya, H.; Fujita, M.; Ikeda, S.; Ando, T. Ultrason. Sonochem. 1996, 3, 157.

20. Hasegawa, T. J. Acoust. Soc. Of Am. 1969, 46, 1139.

21. Pugin, B. Ultrasonics 1987, 25, 49.

22. Zieniuk, J. K.; Chivers, R. C. Ultrasonics 1976, 14, 161.

23. Hardcastle, J. L.; Ball, J. C.; Hong, Q.; Marken, F.; Compton, R. G.; Bull, S. D.; Davies, S. G. Ultrason. Sonochem. 2000, 7, 7.

24. Pereira-Filho, E. R.; Arruda, M. A. Z. Analyst 1999, 124, 1873.

25. Pereira-Filho, E. R.; Petrus, R.; Faria J. A. F.; Arruda, M. A. Z. Lab. Rob. Autom. (submitted)

26. Weissler, A. J. Am. Chem. Soc. 1959, 81, 1077

27. Niemczewski, B. Ultrasonics 1980, 18, 107

28. Mason, T. J. Critical Reports on Applied Chemistry; Vol. 28; Society of Chemical Industry; London, UK, 1990.

29. Kocis S.; Figura, Z. Ultrasonic measurements and technologies; Chapman \& Hall; London, 1996.

30. Entezari M.H.; Kruus, P. Ultrason. Sonochem. 1996, 3, 19.

31. Ney Dental International, Ultrasonik Cleaner: Owner \& Operator's Manual.

Received: July 12, 2000

Published on the web: February 9, 2001

FAPESP helped in meeting the publication costs of this article. 